\title{
Effects of anthropogenic disturbance on richness-dependent stability in Napahai plateau wetland
}

\author{
LI Wei ${ }^{1}$, TAN Rui ${ }^{1}$, WANG Juan ${ }^{2 *}$, DU Fan $^{1} \&$ YANG YuMing ${ }^{2}$ \\ ${ }^{1}$ Yunnan Academy of Biodiversity, Southwest Forestry University, Kunming 650224, China; \\ ${ }^{2}$ Yunnan Academy of Forestry, Key Laboratory of the State Forestry Administration for Conservation of Yunnan Rare, Endangered \& \\ Endemic Plant, Key Laboratory of Yunnan Provincial for Forest Plant Cultivation and Utilization, Kunming 650204, China
}

Received March 25, 2013; accepted April 27, 2013; published online July 22, 2013

\begin{abstract}
Unique plateau wetlands in China provide essential ecosystem functions and services and influence the health, environment and security of the downstream regions. In recent years, these plateau wetlands have experienced significant anthropogenic disturbance, but studies that evaluate the effects of such disturbance on ecological stability are rare. Our study tested how three typical types of human-related activities affect plant richness and ecological stability in Napahai plateau wetland, Shangri-La, China. The results showed that the anthropogenic disturbance had a direct effect on richness, and an indirect effect on stability mediated by richness. Anthropogenic disturbance did not alter the positive relationship between plant richness and community stability, and the stabilizing effect of richness could be explained by statistical averaging, overyielding effect, and component population stability. Our study complements previous studies that tested the richness-stability relationships in synthesized assemblages with richness specifically manipulated and studies that introduced mowing treatment to mimic real anthropogenic disturbance. The results further suggest that necessary steps, such as anthropogenic disturbance mitigation and plant richness conservation, are urgently required for maintaining healthy plateau wetlands and for sustaining their ecosystem functions and services.
\end{abstract}

Napahai plateau wetland, community stability, anthropogenic disturbance, richness-stability relationship, stabilizing mechanisms

Citation: $\quad$ Li W, Tan R, Wang J, et al. Effects of anthropogenic disturbance on richness-dependent stability in Napahai plateau wetland. Chin Sci Bull, 2013, 58: 4120-4125, doi: 10.1007/s11434-013-5954-4

Wetlands are indispensable ecosystems that provide essential ecological functions and services, such as offering key habitats for wildlife, improving water quality and regulating biogeochemical cycles [1-5], and plateau wetlands are unique wetland types of particular importance. In China, most plateau wetlands are located in the upstream regions of major rivers, including the Yangtze River, the Yellow River and the Mekong River. These wetlands directly or indirectly affect the health, environment and security of the downstream regions. Additionally, unlike their common wetland counterparts, most plateau wetlands occur in high-altitude depressions without inflows from nearby rivers or streams, and thus are highly vulnerable to climate change and various disturbance types, especially anthropogenic disturbance

*Corresponding author (email: schima@163.com)
[6,7]. Although the urgent need to protect China's plateau wetlands has been more and more recognized, the basic research on plateau wetlands remains limited.

Anthropogenic disturbance has dramatically influenced a variety of ecological attributes, including species interactions, population dynamics, community structures and ecosystem functions [8-11]. A better understanding of the impacts of anthropogenic disturbance on wetland vegetation stability is particularly important, because wetland plants function as indispensable components: they determine the critical ecological processes and ecosystem services, and their stability status is closed related to the performance and stability of the whole wetland ecosystem [12-15]. We are particularly interested in testing how different forms of anthropogenic disturbance would affect wetland plant richness, ecological stability, as well as the relationship between the 
two for the following reasons: (1) richness-stability relationship remains a central topic of ecological research [16-21]; (2) although a majority of richness-stability studies have shown that richness is vital for ecological stability of synthesized assemblages, we have limited evidence from natural communities that accommodate more non-random species assemblages and heterogeneous environment [22,23]; and (3) there are very few empirical studies that test whether anthropogenic disturbance would strengthen or weaken the stabilizing effect of richness, and through which pathways anthropogenic disturbance and richness would interact and affect stability.

Napahai plateau wetland, located in the northwestern part of Yunnan Province, China, is known for its low-latitude high-altitude topography and magnificent wilderness scenes. However, Napahai plateau wetland has suffered severely from habitat loss and degradation in recent years, mainly caused by humanity's expanding footprint. Because two component parts of Napahai wetland, primary swamps and swampy meadows, are permanently and intermittently wet areas, respectively, they are also less accessible for human activities. In contrast, semi-wet meadows have experienced higher levels of anthropogenic disturbance [24]. Therefore, our study focused on semi-wet meadow areas of Napahai wetland, and three general types of disturbance were identified: (1) tourism-related trampling (TRT): tourism is prosperous in Napahai area, which greatly spurs local economic growth, but also causes ecological and environmental problems; (2) pig foraging activities (PFA): local Tibetan residents practice free range to raise pigs. The pigs frequently dig up the ground for plant roots, and thus cause the death of affected plants; (3) natural turf removal (NTR): it is a common practice for local Tibetan residents to cut and remove the topsoil together with good vegetative covers, and use them as raw materials for wall panels and as decoration materials for roof panels. This practice is devastating as it removes live plants as well as their soil seed pools.

This study is part of a larger project designed to investigate the successional patterns of wetland plant communities and functions of wetland vegetation in maintaining the stability of Yunnan plateau wetland ecosystems. The main purpose of our study is to investigate the effects of aforementioned forms of anthropogenic disturbance on the stability of wetland plant communities. Specifically, we address the following questions: (1) Does anthropogenic disturbance affect plant richness? (2) Does anthropogenic disturbance affect stability directly, indirectly, or in both ways (Figure 1)? (3) Does richness affect stability in natural communities under anthropogenic disturbance? (4) If so, what are possible mechanisms for the stabilizing effect of richness?

\section{Materials and methods}

Our study site is located at the semi-wet meadow areas (a)

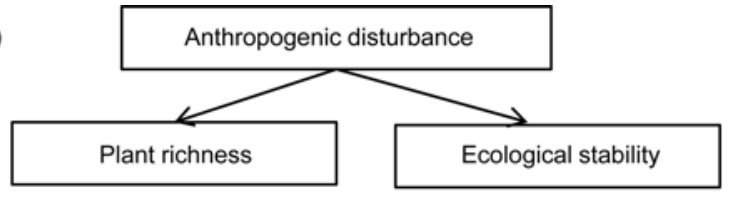

(b)

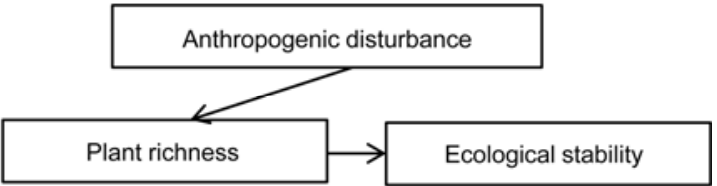

(c)

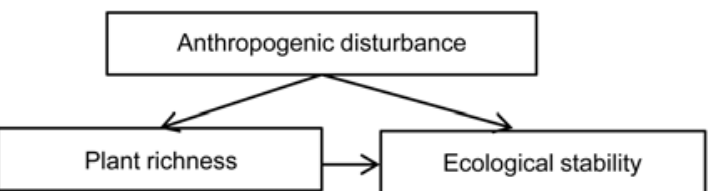

Figure 1 Schematic figure of three alternative pathways among disturbance, richness and stability. (a) Disturbance has a direct effect on stability; (b) disturbance has an indirect effect on stability mediated via richness; (c) disturbance has both direct and indirect effect on stability.

$\left(27^{\circ} 51^{\prime} \mathrm{N}, 9^{\circ} 39^{\prime} \mathrm{E}, 3269\right.$ a.s.l) of Napahai plateau wetland, Shangri-La. Napahai wetland experiences dry and wet seasons annually, with the wet season between June and October, and the dry season between November and May. Average annual precipitation is $606.6 \mathrm{~mm}$, and average monthly temperature ranges from $-3.7^{\circ} \mathrm{C}$ in January to $13.2^{\circ} \mathrm{C}$ in July [7,24].

We carried out the preliminary survey in 2009 to choose study plots that were influenced by representative disturbance types, with three replicates for each type. Since ShangriLa Forestry Bureau and Shangri-La Tourism Administration have taken actions to curb anthropogenic pressure on the wetland ecosystem since 2008, our chosen experimental plots are currently at the recovering phase from earlier disturbance. We began surveying the selected $5 \mathrm{~m} \times 5 \mathrm{~m}$ plots under these three disturbance regimes in 2010 for three consecutive years. Within each year, we sampled each $1 \mathrm{~m} \times$ $1 \mathrm{~m}$ subplot within each $5 \mathrm{~m} \times 5 \mathrm{~m}$ plot three times (i.e., in spring, summer and fall, respectively). Species richness was recorded as the number of plant species found in each subplot, and the abundance of individual species in each subplot was also recorded. Since plant species composition varied seasonally and yearly (unpublished data), we only used data collected during the summer season when most plants experience maximum growth. Also, species that occurred in at least two replicate plots and spanned at least two summer seasons were used for stability analysis. Additionally, because some plots were under the influence of seasonal flooding, they were excluded for further analysis to minimize the effects of environmental fluctuations.

We use temporal variability to assess stability, and temporal variability is commonly measured as the coefficient of variation $(100 \times \delta / \mu)$ where $\delta$ is the standard deviation and $\mu$ 
is the mean of an aggregate community property over a time period $[25,26]$. Based on this definition, temporal variability is inversely related to temporal stability, and higher temporal variability indicates lower temporal stability. For our study, community temporal variability is measured as the ratio of standard deviation of total abundance to its mean value during the three consecutive years. Similarly, population variability is measured as the standard deviation of species abundance divided by its mean value. The value is averaged across the populations to obtain a single measure of mean population variability for each sampled plot.

The statistical analyses included several steps. First, MANOVA was used to test the effect of disturbance on richness and stability together. Given that there was a significant effect on the multivariate response, ANOVA was then performed to test whether disturbance showed significant effects on richness and stability, respectively, followed by ANCOVA to test the effects of both disturbance (the categorical variable) and richness (the continuous variable) on stability. Also, structural equation modeling (SEM) was applied as an alternative analysis approach. Post hoc tests were conducted using the Tukey's HSD test. All abundances were log-transformed to reduce heteroscedasticity. We then evaluated four potential mechanisms associated with the observed richness-stability relationships. Statistical averaging occurs when the variability of total abundance of plants decreases with increasing richness. This is because variations in population dynamics among species tend to offset each other. There is evidence for statistical averaging when the temporal variance in the total abundance scaling with the mean abundance yields a slope greater than 1 . This is because theoretical studies using a series of simulations have shown that when the temporal variance of an aggregate community property, $\sigma^{2}$, scales with its mean value, $m$, according to the power function of $\sigma^{2}=\mathrm{cm}^{z}$, if $z=1$, diversity has no effect on community stability; if $z<1$, more diverse communities are less stable; and if $z>1$, the tendency for stability to increase with diversity necessarily holds [27,28]. Covariance effect indicates the way species interact with their environment, and negative covariance values suggest that species respond asynchronously to the environment to reduce average fluctuations. Therefore, by checking the magnitude and the sign of summed covariance along with increasing richness, a negative relationship between summed covariance and species richness would support this mechanism [29,30]. Overyielding refers to an increase in total abundance with richness, which tends to stabilize community fluctuations, and this mechanism is evaluated by examining whether a positive relationship exists between total abundance and plant richness [26,30]. Lastly, component populations with fewer variable characteristics contribute to a less variable community. Therefore, a positive relationship between population variability and community variability indicates that richness could affect community stability via its effect on component populations [31,32].

\section{Results}

MANOVA showed significant effect of disturbance on the combined response of community stability and richness (Pillai's $T=1.16, F=4.14, P=0.02$ ). Univariate ANOVA showed that disturbance had a significant effect on richness $\left(F_{2,6}=19.62, P<0.01\right.$; Figure 2$)$, but not on stability $\left(F_{2,6}=\right.$ $3.53, P=0.08)$. Specifically, TRT plots supported higher levels of plant richness than either PFA or NTR plots, whereas there was no significant difference between the latter two (Figure 2). ANCOVA test further showed that the final model only contained richness, but not disturbance as independent variable, irrespective of the relative order of richness variable to disturbance variable in the comparative models. Additionally, TRT plots with higher richness also had higher stability than PFA or NTR plots with lower richness (Figure 3). The SEM analysis demonstrated the lack of a direct effect of disturbance on variability. In contrast, effect strengths measured for the effect of disturbance on richness was -0.44 , and effect strengths measured for the

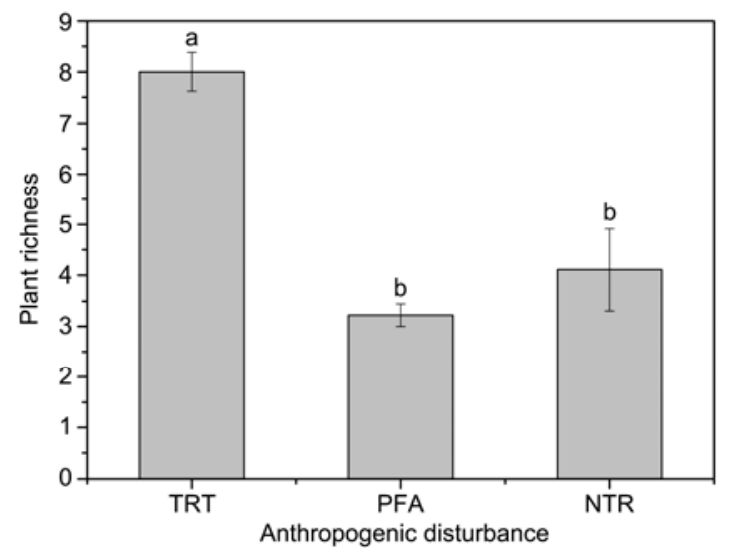

Figure 2 Plant richness under different anthropogenic disturbance regimes. Different small letters indicate statistically significant difference by Tukey's test. Shown are mean values $\pm 1 \mathrm{SE}$.

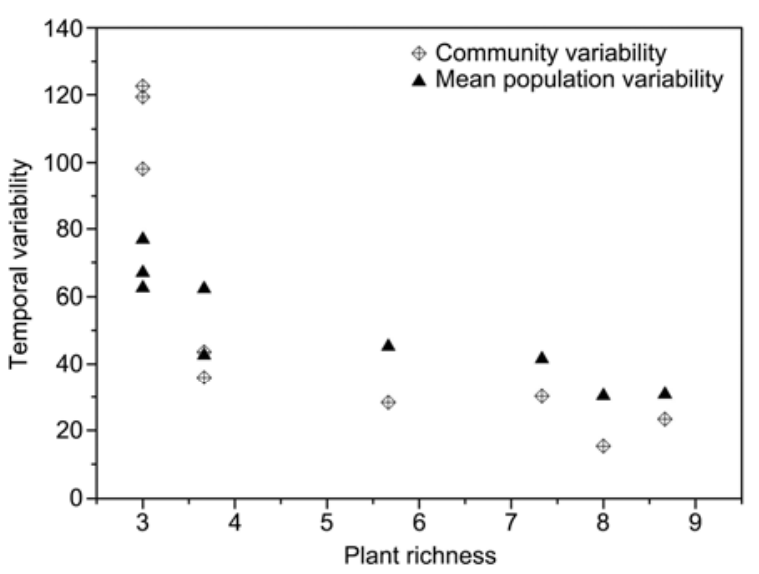

Figure 3 Effects of plant richness on temporal variability at both community and population organizational levels. 
effect of richness on variability was -0.86 (Figure S1). Therefore, evidence for the significant effect of disturbance on richness, and the significant effect of richness on variability was conspicuous, but the direct effect of disturbance on variability was not detected, confirming our previous analysis results. Similarly, at the population level, all analyses showed that richness $\left(F_{2,6}=24.63, P<0.01\right)$, not disturbance $\left(F_{2,6}=4.17, P=0.17\right)$, significantly affected mean population variability, with a negative relationship between mean plant richness and mean population variability (Figure 3).

The slope of the mean-variance scaling relationship averaged across all plant species was 1.48 (Figure 4(a)), supporting the role of statistical averaging in stabilizing community abundance with increasing richness. The summed covariance had both positive and negative values, and there was no clear pattern between summed covariance and richness (Figure 4(b)). Therefore, covariance effect was disproved in our study system. The logarithms of the mean abundance increased with richness significantly (Figure 4(c)), supporting the overyielding effect. There was a statistically significant positive relationship between population and commu- nity variability, indicative of the influence of population stability on community stability (Figure 4(d)).

\section{Discussion and conclusions}

In this study, plant richness in TRT plots was much higher than that in PFA or NTR plots. Clearly, both pig foraging and turf removal activities have posed severe threats to plant richness and produced long-lasting negative effects on vegetation recovery. Pigs frequently dug up the ground and consumed plant roots, and their foraging behavior seriously damaged or destroyed plants. In contrast, anthropogenic removal activities had more devastating impacts because they completely destroyed the aboveground vegetation and the belowground soil seed pools, making the recovery of vegetation even more difficult.

The study also showed that plant richness, not disturbance, directly affected community stability. Since disturbance was the major factor that caused variation in plant richness, the absence of direct effect of disturbance on stability suggests
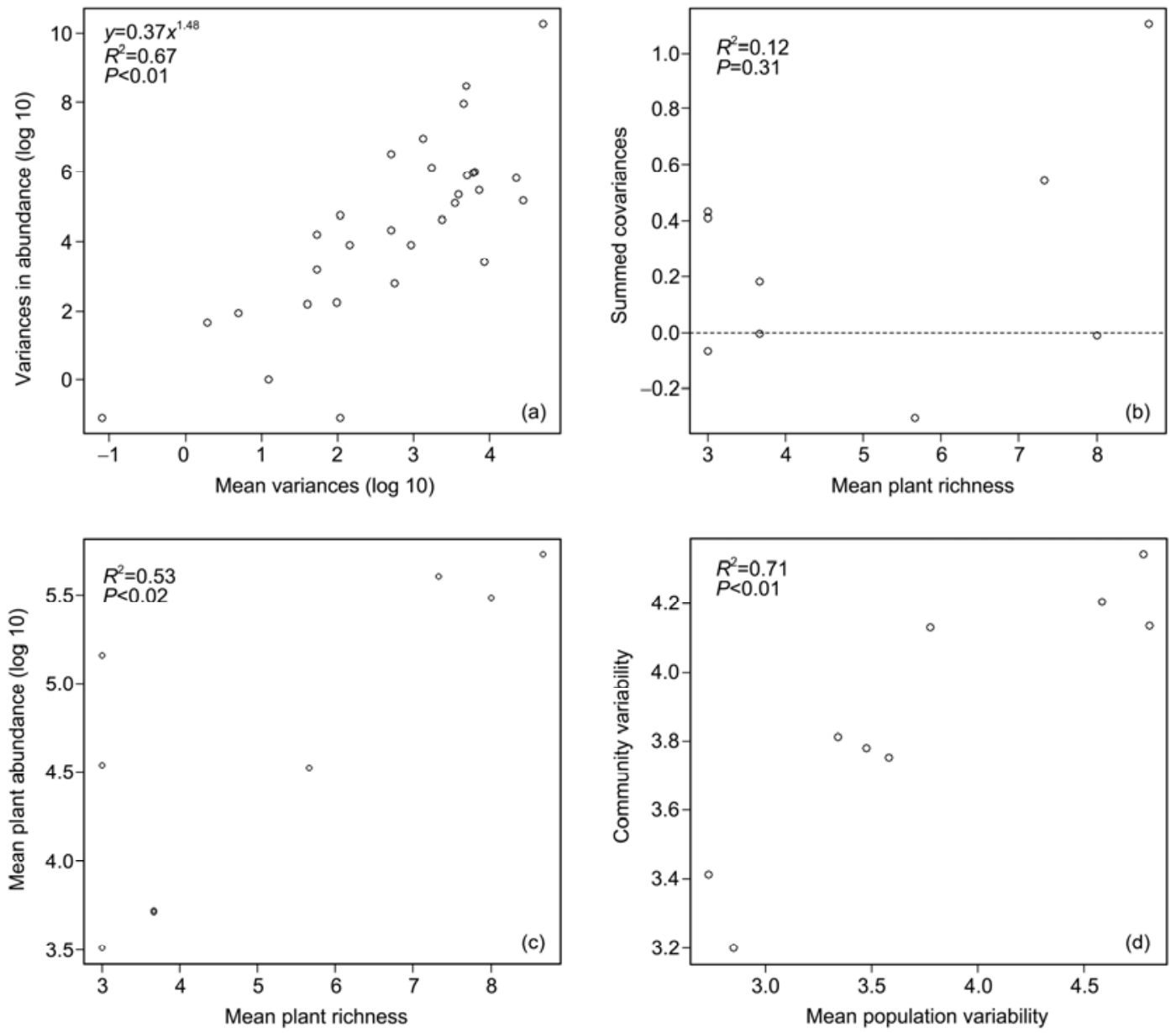

Figure 4 A mechanistic examination of the stabilizing effect of richness. (a) Log-log plot of variances in plant abundance vs. mean plant abundance. (b) Summed covariances in plant abundance vs. mean plant richness. Summed covariances showed no general relationship with richness. (c) The relationship between mean plant abundance and mean richness. (d) The relationship between community variability and mean population variability. 
that disturbance effect could have been mediated by richness (Figure 1). Finding this indirect link between disturbance and stability is important. On the surface, anthropogenic disturbance seemed to be unrelated to temporal stability of wetland plant communities, but disturbance could be the ultimate cause for the natural variation of plant richness as well as community stability, although in an indirect way for the latter. Over the past decades, the majority of studies have tested the relation between species richness and community stability. However, most of these studies used synthesized assemblages so that species richness could be directly manipulated. Such experimental design could be useful for identifying the effect of richness on stability. However, since richness was manipulated independent of variation in other factors, these studies failed to include the realism that richness might be affected by factors such as anthropogenic disturbance as it was observed in our case. Recently, a limited number of studies have begun to manipulate environmental factors (e.g., nutrient enrichment, biomass harvesting) to test the effect of resulting variation in species richness on stability [33,34]. In line with the results of these studies, we also found a persistently positive relationship between species richness and community stability under anthropogenic disturbance. However, our study included more types of real anthropogenic disturbance under more natural settings, as compared to studies that included mowing treatment to mimic the main form of disturbance.

The positive relationship between plant richness and community stability observed in this study was in agreement with the findings of many other studies [26,29,35-42]. We further explored the possible mechanisms, and found that statistical averaging, overyielding, and component population effects were likely mechanisms to account for the stabilizing effect of plant richness. Our results did not support the covariance effect given that not all covariance values were negative, and there was not a decreasing trend of covariances with increasing richness. It is worth noting that we found a positive relationship between population- and community-level stability. Previous studies reported positive $[37,39,41]$, negative $[26,29,40]$, and neutral relationships $[36,38,42]$ between the two, but the causes of these different patterns are still unknown. Future work should examine the general nature of the relationships and elucidate the associated mechanisms.

Our results clearly showed that plant richness is vital for community stability of plateau wetland. Besides that, plant richness contributes significantly to ecosystem functions and services, and disturbance-caused species loss would undoubtedly have far-reaching negative impacts. In Napahai plateau wetland, different types of anthropogenic disturbance not only impair biota and stability but also change ecosystem functionality. Tourism-induced trampling can increase soil bulk density and decrease soil porosity and water holding capacity, thus severely affecting water storage and flood regulation functions of wetland soils [43]. Pig foraging and turf removal activities cause the death of many perennial plants, which otherwise offer vital food sources and security covers for species at other tropic levels. Therefore, the damage to these perennial plants will inevitably affect the survival of other coexisting species. Moreover, perennial plants have their roots alive through the long and cold winter when the tops die, and the massive belowground parts with nutrient storage functions are essential for successful resprouting in the following spring. Additionally, the intertwined root systems belowground reinforce the capability of the soil to withstand water flow, and thus effectively reduce soil erosion as deep snowpacks melt in the spring to cause a dramatic increase in water flow [44].

Like other types of wetlands, plateau wetlands offer important ecosystem functions (e.g., carbon sequestration, nutrient cycling regulation, soil fertility maintenance) and services (e.g., water quality improvement, food and energy supply). However, many plateau wetlands have experienced significant anthropogenic disturbance, just as what Napahai plateau wetland has suffered at the hands of humans. Without adequate legal enforcement and strict regulation, anthropogenic disturbance would further impoverish species richness and then dismantle ecosystem functions, eventually leading to the collapse of important ecosystem service upon which people depend. Actually, a recent global synthesis reveals that the loss of species richness can negatively affect ecosystems as much as climate change, pollution and other main forms of environmental stress do [45]. Therefore, preserving the abundance and richness of plant communities is necessary for maintaining healthy plateau wetlands and for sustaining their essential ecosystem functions and services. To accomplish this goal, a closer and stronger collaboration among scientists, politicians and government authorities is urgently needed in the future.

In conclusion, anthropogenic disturbance caused the change of plant richness, with TRT plots supporting higher levels of plant richness than either PFA or NTR plots. Plant richness affected stability directly, whereas anthropogenic disturbance affected stability indirectly mediated by richness. There was a tight coupling between plant richness and community stability, and this positive richness-stability relationship persisted for the studied natural plant communities under different anthropogenic disturbance regimes. Therefore, this present study complements previous studies that used synthesized assemblages and overlooked external driver factors. Effects of statistical averaging, overyielding, and component population stability were identified as possible mechanisms involved that could account for the stabilizing effects of richness on community stability.

We thank Yu Qi, Yang Chenxuan, Guan Jiajie and Pan Wenwen for assistance with species identifications and measurements. This work was supported by National Natural Science Foundation of China and Yunnan Province (U0933601), National Basic Research Program of China (2010CB434807), and the Middle Aged Academic and Technical Leader Project of Yunnan Province (2010CI016). 
1 Howard-Williams C. Cycling and nutrient retention of nitrogen and phosphorus in wetlands: A theoretical and applied perspective. Freshwater Biol, 1985, 15: 391-431

2 Gren I M, Folke C, Turner R K, et al. Primary and secondary values of wetland ecosystems. Environ Resour Econ, 1994, 4: 55-74

3 Woodward R T, Wui Y S. The economic value of wetland services: A meta-analysis. Ecol Econ, 2001, 37: 257-270

4 Brander L M, Florax R, Vermaat J E. The empirics of wetland valuation: A comprehensive summary and a meta-analysis of the literature. Environ Resour Econ, 2006, 33: 223-250

5 Mitsch W J, Gosselink J G. Wetlands. Hoboken (New Jersey): John Wiley \& Sons, 2007

6 Bai J H. Plateau Wetlands in China (in Chinese). Beijing: Chinese Forestry Press, 2008

7 Tian K, Guo H J, Yang Y M. Ecological Structures and Functions of Plateau Wetlands in China (in Chinese). Beijing: Science Press, 2009

8 Vitousek P M. Human domination of Earth's ecosystems. Science, 1997, 277: 494-499

9 Sala O E, Chapin F S, Armesto J J, et al. Global biodiversity scenarios for the year 2100. Science, 2000, 287: 1770-1774

10 Tilman D, Lehman C. Human-caused environmental change: Impacts on plant diversity and evolution. Proc Natl Acad Sci USA, 2001, 98: 5433-5440

11 Peres C A, Barlow J, Laurance W F. Detecting anthropogenic disturbance in tropical forests. Trends Ecol Evol, 2006, 21: 227-229

12 Engelhardt A M, Ritchie M E. Effects of macrophyte species richness on wetland ecosystem functioning and services. Nature, 2001, 411: 687-689

13 Pfisterer A B, Schmid B. Diversity-dependent production can decrease the stability of ecosystem functioning. Nature, 2002, 416: 84-86

14 Griffin J N, O'Gorman E J, Emmerson M C, et al. Biodiversity and The Stability of Ecosystem Functioning. Oxford: Oxford University Press, 2009

15 Steudel B, Hautier Y, Hector A, et al. Diverse marsh plant communities are more consistently productive across a range of different environmental conditions through functional complementarily. J Appl Ecol, 2011, 48: 1117-1124

16 MacArthur R H. Fluctuations of animal populations and a measure of community stability. Ecology, 1955, 36: 533-536

17 May R M. Stability and Complexity in Model Ecosystems. Princeton: Princeton University Press, 1973

18 Pimm S L. The complexity and stability of ecosystems. Nature, 1984, 307: 321-326

19 Tilman D. The ecological consequences of changes in biodiversity: A search for general principles. Ecology, 1999, 80: 1455-1474

20 McCann K S. The diversity-stability debate. Nature, 2000, 405: 228-233

21 Ives A R, Carpenter S R. Stability and diversity of ecosystems. Science, 2007, 317: 58-62

22 Grace J B, Anderson T M, Smith M D, et al. Does species diversity limit productivity in natural grassland communities? Ecol Lett, 2007, 10: 680-689

23 Jiang L, Wan S Q, Li L H. Species diversity and productivity: Why do results of diversity-manipulation experiments differ from natural patterns? J Ecol, 2009, 97: 603-608

24 Xiao D R, Tian K, Yuan H, et al. Landscape diversity of Napahai wetland plant community in Northwest Yunnan of China (in Chinese).
Chin J Ecol, 2007, 26: 1171-1176

25 Loreau M. From Populations to Ecosystems: Theoretical Foundations for a New Ecological Synthesis. Princeton: Princeton University Press, 2010

26 Tilman D, Reich P B, Knops J M H. Biodiversity and ecosystem stability in a decade-long grassland experiment. Nature, 2006, 441: 629-632

27 Doak D F, Bigger D, Harding E K, et al. The statistical inevitability of stability-diversity relationships in community ecology. Am Nat, 1998, 151: 264-276

28 Tilman D, Lehman C L, Bristow C E. Diversity-stability relationships: Statistical inevitability or ecological consequence. Am Nat, 1998, 151: 277-282

29 Tilman D. Biodiversity: Population versus ecosystem stability. Ecology, 1996, 77: 350-363

30 Lehman C L, Tilman D. Biodiversity, stability, and productivity in competitive communities. Am Nat, 2000, 156: 534-552

31 Ives A R, Gross K, Klug J L. Stability and variability in competitive communities. Science, 1999, 286: 542-544

32 DeWoody Y D, Swihart R K, Craig B A, et al. Diversity and stability in communities structured by asymmetric resource allocation. Am Nat, 2003, 162: 514-527

33 Grman E, Lau J A, Schoolmaster D R, et al. Mechanisms contributing to stability in ecosystem function depend on the environmental context. Ecol Lett, 2010, 13: 1400-1410

34 Yang H J, Jiang L, Li L H, et al. Diversity-dependent stability under mowing and nutrient addition: Evidence from a 7-year grassland experiment. Ecol Lett, 2012, 15: 619-626

35 Tilman D, Downing J A. Biodiversity and stability in grasslands. Nature, 1994, 367: 363-365

36 McGrady-Steed J, Morin P J. Biodiversity, density compensation, and the dynamics of populations and functional groups. Ecology, 2000, 81: 361-373

37 Valone T J, Hoffman C D. Population stability is higher in more diverse annual plant communities. Ecol Lett, 2003, 6: 90-95

38 Steiner C F, Long Z T, Krumins J A, et al. Temporal stability of aquatic food webs: Partitioning the effects of species richness, species composition and enrichment. Ecol Lett, 2005, 8: 819-828

39 Vogt R J, Romanuk T N, Kolasa J. Species richness-variability relationships in multi-trophic aquatic microcosms. Oikos, 2006, 113: 55-66

40 van Ruijven J, Berendse F. Contrasting effects of diversity on the temporal stability of plant populations. Oikos, 2007, 116: 1323-1330

41 Proulx R, Wirth C, Voigt W, et al. Diversity promotes temporal stability across levels of ecosystem organization in experimental grasslands. PLoS One, 2010, 5: e13382

42 Wardle D A, Bonner K I, Barker G M, et al. Plant removals in perennial grassland: Vegetation dynamics, decomposers, soil biodiversity and ecosystem properties. Ecol Monogr, 1999, 69: 535-568

43 Zhang K, Tian K, Lu X G, et al. Impacts of tourism on water storage and regulation of meadow soil in Napahai lakeshore wetlands (in Chinese). Adv Water Sci, 2009, 20: 800-805

44 Körner C. Alpine Plant Life: Functional Plant Ecology of High Mountain Ecosystem. 2nd ed. Berlin, Heidelberg, New York: Springere Verlag, 2003

45 Hooper D U, Adair E C, Cardinale B J, et al. A global synthesis reveals biodiversity loss as a major driver of ecosystem change. Nature, 2012, 486: 105-110

Open Access This article is distributed under the terms of the Creative Commons Attribution License which permits any use, distribution, and reproduction in any medium, provided the original author(s) and source are credited.

\section{Supporting Information}

Figure S1 Structural equation modeling (SEM) method for analyzing multivariate relationships involving disturbance, richness and community variability.

The supporting information is available online at csb.scichina.com and www.springerlink.com. The supporting materials are published as submitted, without typesetting or editing. The responsibility for scientific accuracy and content remains entirely with the authors. 